\title{
Consumer Preferences Concerning Potentially Unsafe Food
}

\author{
Victoria Chatten ${ }^{1}$, Bobby Sidhu ${ }^{2}$, Lorraine McIntyre ${ }^{3}$ \\ ${ }^{1}$ Lead Author, B. Tech Student, School of Health Sciences, British Columbia Institute of Technology, 3700 Willingdon Ave, Burnaby, BC, V5G 3H2 \\ ${ }^{2}$ Supervisor, School of Health Sciences, British Columbia Institute of Technology, 3700 Willingdon Ave, Burnaby, BC, V5G 3H2 \\ 3 Contributor, British Columbia Centre for Disease Control, 655 West $12^{\text {th }}$ Ave, Vancouver, BC, V5Z 4R4
}

\begin{abstract}
:
BACKGROUND: Recent studies have shown that the reasons behind consumers' preferences towards certain food products are extremely dynamic. Organic foods, raw milk products and bottled water are a few products discussed in this paper that have gone under debate regarding their safety versus their perceived health benefits.

METHODS: Over 100 people participated in an exclusively online self-administered questionnaire. The questionnaire was publicized through both email and social media. Participants responded to questions regarding their food preferences of a variety of food types.

RESULTS: It was found that there was a statistically significant association between education and preferences towards both milk products and organic/non-organic food products. No other demographic (setting, gender, age) were found to be associated with food preferences. It was also found that all food preferences were associated with the reasoning for that specific food preference, with the exception of cut/whole fruit.

CONCLUSION: The association between food preferences and its reasoning concludes that consumers who prefer opposing products do so for extremely different reasons. Consumers that prefer the more risky food products mainly do so for taste and potential health benefits. Public health officials need to ensure that consumers that prefer riskier products thoroughly understand the risks, so that they themselves can then truly compare the benefits of taste or perceived "healthiness" with the consequences of potential contamination and illness.
\end{abstract}

Key words: survey, food preferences, consumers, food choice, food safety

\section{Introduction}

Throughout the many processes that take food from a raw material to the edible product on a plate there are numerous chances for contamination to occur. Depending on these processes and the nature of the food, some food products are inherently more at risk of contamination than others.

Consumers can become misinformed about the inherent risks of available food products through a variety of ways. Incorrect information or misunderstandings can lead not only to consumers choosing a risky food product but can even lead to the creation of unrealistic food programs and regulations due to misinformed pressure groups (International Association for Food Protection, 2011).

People not only alter their eating habits due to negative effects associated with food but also due to positive effects that the media or other sources claim. Consumers may choose a food for its perceived health benefits or taste, rather than its safety.

The reason behind a consumer's choice in potentially unsafe food is extremely dynamic. It depends on one's confidence in food safety, one's relationship with food information sources, and one's general food preferences and habits. If the basis behind consumers' preferences towards unsafe food items is determined it can be used to develop effective risk communication messages that can lead to a decrease in food or waterborne illnesses (De Jonge, van Trijp, Renes, \& Frewer, 2007).

This paper describes an examination of consumers' food preferences when given a choice between safe and potentially unsafe food through a survey approach. It also examines the factors that lead to specific food preferences.

\section{Literature Review}

\section{Consumers' confidence in food safety}

The degree to which a consumer is confident in the safety of food is dependent on a multitude of factors (De Jonge, van Trijp, Renes, \& Frewer, 2007). The two main factors that were found to influence confidence in food safety are the trust in various regulators of food production and individual characteristics of the 
consumer. Trust is an important issue and it is one that was found to be recurring when reviewing the topic of consumer confidence in food safety. The amount of trust a consumer held with governmental bodies and food manufacturers positively correlated to the amount of confidence a consumer held with the safety of food (De Jonge, van Trijp, Renes, \& Frewer, 2007). In agreement with this fact, governments and food manufacturers are perceived to be the most responsible parties for the safety of food. It is suggested by some that food manufacturers should communicate food safety as a part of their social responsibilities to the public (Rohr, Luddecke, Drusch, Muller, \& Alvensleben, 2005). Communicating concern for the well-being of consumers and being attentive to the issue of food safety are necessities if organizations wish to generate consumer confidence (De Jonge, van Trijp, van der Lans, Renes, \& Frewer, 2008).

A commendable example of food safety communication by a food manufacturer would be in 2008 by Maple Leaf Foods. In late August, 2008, the president of Maple Leaf Foods accurately communicated the company's situation of a Listeriosis outbreak along with future food safety assurance of their products (Greenberg \& Elliot, 2009). Even though the company was responsible for unsafe food this communication between the company and consumers allowed for trust and confidence to rebuild.

In addition to trust, individual characteristics such as personality, age, and education also have an effect on consumer confidence. It was found that consumers that have low confidence in other areas, or who are worrisome in general, are more likely to have low confidence in the safety of food. It also found that elderly populations and uneducated consumers were less confident in the safety of food (De Jonge, van Trijp, Renes, \& Frewer, 2007).

Individuals who remember food safety incidences, such as foodborne illness outbreaks, seem to be equally confident in the safety of food than those who could not recall this type of event. This indicates that information regarding food safety events may not influence consumers' confidence in food safety (De Jonge, van Trijp, Renes, \& Frewer, 2007).

The change in a consumer's confidence in food safety from either an incidence that led to mistrust in an organization or a change in personal characteristics could have detrimental effects on the food choices of that consumer (De Jonge, van Trijp, van der Lans, Renes, \& Frewer, 2008). An incidence of mistrust in governmental bodies or food manufacturers could be one of the reasons behind consumers' choosing food straight from the farm, as the responsibilities of manufacturers and some government agencies are eliminated when farmers sell straight to consumers.
This study explored which food items participants prefer to purchase and consume mainly due to their perceived safety of that product. The study attempted to discover whether or not food bought straight from farmers was done so to eliminate the risk perceived to be associated with large manufacturers.

\section{Sources of information for consumers}

As mentioned above, it appears that consumers place the most trust and responsibility of food safety on to the government and food manufacturers. This however, is not the case when it comes to a consumer's perceived reliability of sources of information regarding food safety. As the amount of influence a source may have on the public is dependent on how reliable the public believes that source to be (Rohr, Luddecke, Drusch, Muller, \& Alvensleben, 2005). In a study in 2004, consumers ranked consumer and environmental organizations as the most trusted for sources of information regarding food safety and the government was ranked least trustworthy. The most trusted sources of information included media such as television and newspaper as well as consumer associations (Rosati, \& Saba, 2004). Others state that a leading source of information is actually word of mouth, especially between friends and family (Agriculture Canada, 2007).

Consumers across the world seem to be in agreement with these facts as in a European survey created by TSN Opinion and Social for the European Food Safety Authority in 2010, it was found that the public's confidence levels in national governments appeared to be the lowest compared to all others. In this study, the most confidence was given to health professions and personal contacts such as family and friends (TSN Opinion and Social, 2010).

Consumers will react to both negative and positive sources of information regarding food safety (Dillaway, Messer, Bernard, \& Kaiser, 2011). Negative information can change buying habits independent of the source of information, as information from a non-scientific source was able to influence consumers in this way (Dillaway, Messer, Bernard, \& Kaiser, 2011). The study performed by Dillaway and colleagues in 2011, followed consumers' behaviours after magazine articles were read regarding food safety. They found that the information dispensed changed the consumers' behaviours for 7 weeks. However the impact of food safety information on consumers over longer time periods is not well researched.

In a separate study where consumers were surveyed regarding knowledge on food safety incidences only half of the sample population could recall any recent past food safety incidence (McFadden et al., 2010). A slightly larger percentage of consumers $(60 \%)$ were aware of the current outbreak involving Salmonella found on tomatoes and peppers. In this study, 60\% was 
deemed an indication that the public was well informed. However when thought of in reverse, many members of the public (40\%) were unaware of the current outbreak that could have easily affected them, as it surrounded common food items (McFadden et al., 2010). It is noted that many consumers don't actually actively attempt to find information regarding food safety but rather simply wait to receive it (Agriculture Canada, 2007).

Although this specific study did not explore participants' sources of food safety information, analysis was able to indicate proportions and percentages of the participants correct and incorrect in their knowledge of food safety of certain products.

\section{Basis of consumers' food preferences}

When considering the reason behind a consumer's food choice many variables come into play especially when considering food safety. Food choices depend on a consumer's internal attributes such as personal history, mindset, past experiences, habits, and time and effort available (Saulo, \& Moskowitz, 2011). Consumers also appear to be influenced by external factors such as social images, symbolic brands and the behaviour of other consumers (Franchi, 2012). Other consumers, especially those that appear as well informed are followed by consumers that may not be well informed. The followers mirror the food choices of the "informed" leaders even if the leaders' choices are based on incorrect or false information (Agriculture Canada, 2007).

An example of a perceived informed leader is Dr. Weston Price, an American nutritional pioneer who promoted the consumption of raw milk. Advocacy for raw milk is performed through The Weston A. Price Foundation and their project; A Campaign for Real Milk. Through this platform, Dr. Price highly idolizes the practice of drinking raw milk, and condemns the process of pasteurization (The Weston A. Price Foundation, 2013). The safety concerning milk products is discussed later in this report.

These internal and external influences of food choice behaviours and routines are distinct for every consumer. It is stated by M. Franchi that food choices develop throughout a consumer's life and determine how they experience food; these experiences then, in turn, reinforce food choices which then become food habits (2012). Once something becomes a habit it becomes difficult to change, which maybe the cause of someone consuming a food item they know is risky. Another reason a consumer is likely to engage in risky behaviour in terms of food choice is because they believe they are unlikely to be susceptible to foodborne illness (Saulo, \& Moskowitz, 2011).

One theory revolves around the statement that there are two main types of food consumers: price sensitive and safety sensitive (Rohr, Luddecke, Drusch, Muller,
\& Alvensleben, 2005). Price sensitive consumers will not be as concerned about the safety of a food in terms of place of purchase, production process, or origin (Rohr, Luddecke, Drusch, Muller, \& Alvensleben, 2005). In this study participants were asked whether price, safety, or other reasons were behind their food choice. If price is a reason for a consumer to purchase an unsafe food product over a safer alternative, then changes should be put in place to ensure safe products become more economically preferred.

Consumers are beginning to follow a relatively new food preference trend that is making their food choices slightly simpler by just one word; organic. Consumers are beginning to buy organic foods because they are perceived to be more nutritious than non-organic food. They are perceived to be more nutritious because the lack of use of chemicals is seen as natural and natural is assumed to be healthy and healthy proposes more nutrition (Agriculture Canada, 2007).

There is ongoing debate on the risks and benefits of organic food that is out of the scope of this study. However, risks do exist with natural and organic products that should not be ignored by food companies. For instance the juice company Odwalla was a part of the beginning movement towards organic products. Odwalla believed that pasteurization of its fruit juices reduced the fresh and organic qualities of its products (Melvin, 2010). This lack of pasteurization unfortunately led Odwalla juice to be the cause of a large E.coli O157:H7 outbreak in 1996, in the United States and parts of Canada.

\section{Case study: raw dairy products}

Simultaneously as consumers increase their demand for less processed foods they also increase their demand for raw dairy products. Those who promote raw dairy products claim they not only taste better but have increased health benefits (Jay-Russell, 2010). Raw milk supporters endorse that while one is increasing their vitamin intake by consuming raw milk products they are also supporting local and small dairy farms. The advantages of consuming raw milk products may appear countless. However, public health officials take an opposing view as they declare the numerous risks that go hand in hand with these products. Public health officials have noted that although the consumption of raw dairy products may be a personal choice it can be a source of communicable disease (Jay-Russell, 2010). People that choose to consume raw milk, of which may be contaminated with E.coli O157:H7, could not only harm themselves but potentially pass on the pathogen through the fecal-oral route to someone who did not intend to consume the raw product. The movement towards raw milk products has also been tied to a movement toward mistrusting the government and agriculture industries which could be detrimental as 
noted above that trust is a relevant issue in food safety (Jay-Russell, 2010).

In Canada, raw milk is illegal to sell in Canada, under Health Canada's Food and Drugs Act, however it is permitted to sell products made with raw milk. It appears that raw dairy products such as raw milk cheeses are actively sought after by consumers. When consumers had a choice between labelled raw milk cheeses and pasteurized milk cheeses a significant amount preferred the raw milk cheese (Colonna, Durham, \& Meunier-Goddick, 2011). When the two types of cheeses were offered without any labels consumers preferred both cheeses equally. This suggested that a raw milk label on a cheese enhances consumer's perception of the quality and taste of the cheese. Many of the consumers who preferred raw milk cheeses had knowledge that this type of cheese was less safe, but they also thought it had better quality than the pasteurized milk cheeses (Colonna, Durham, \& Meunier-Goddick, 2011).

The results of this study will indicate the true reasons for why consumers may prefer less safe foods over their safer alternatives. Results will allow for appropriate risk messaging to begin that will inform and target reason that outweigh safety, such as taste, health benefits or accessibility.

\section{Case study: bottled vs tap water}

Similarly to the increase in popular demand for raw dairy products there is an increase in the consumption of bottled water. The trend to choose bottled water over tap water has been growing for many years (Ward et al., 2009).

In the United States consumers' perception of tap water safety was found to be associated to their bottled water use (Hu, Morton, \& Mahler, 2011). Consumers who believed that their municipal tap water was unsafe were more likely to purchase bottled water for their water needs. These US consumers perceived their source of tap water to be unsafe when in fact it was safe, in fact potentially safer than the bottled water they were consuming.

A defining water fact that the public may not know is that tap water is usually more strictly monitored and regulated than bottled water. In places such as British Columbia, Canada all municipal systems that provide tap water to the public are required by law to monitor water quality in compliance with the Drinking Water Protection Act and to report the results to its consumers (Copes, Evans, \& Verhille, 2009). Whereas, bottled water manufacturers are regulated under the Food and Drug Act in Canada and are subject to little monitoring and are only required to meet label restrictions and are not required to report monitoring results to any authority (Copes, Evans, \& Verhille, 2009). Tap water also contains the benefit of providing chlorine residual, whereas bottled water can be subject to contamination during transportation or storage (Copes, Evans, \& Verhille, 2009).

Overall the truth regarding food safety and food risks may be misinterpreted or may not reach the public accurately. The public's confidence in food safety alters the public's choice in foods. A consumer may or may not prefer a safer food, and this can be due to a variety of complex reasons that are reviewed in this study.

\section{Methods}

A survey was created to obtain data for this research project. The survey was an online self-administered questionnaire, distributed through email and social media. It questioned and obtained information from a sample of people in order to reflect the food preferences and behaviours of the Canadian population. A single survey, titled 'The Consumer Food Preference Survey' was completed by all the participants of this study, and no questions or aspects of the survey were changed during the data collection period. Data obtained through the survey included demographics, food preferences, and the reason behind the respondents' preferences for certain food products over alternatives.

Acceptable random distribution of the survey was obtained through the snowball effect (Heacock \& Sidhu, 2013). Validity was ensured through creating responses that were distinct alternatives and one-dimensional (Fowler, 2002). In addition a pilot study was conducted prior to final distribution to increase validity and reliability of the survey. For ethical considerations the survey for this study was voluntary and confidentiality was guaranteed for every participant. Each participant was required to read an informed consent letter prior to participation in the study. Each participant was also asked to acknowledge their consent. A cover letter was sent out through email that encouraged the public to participate in this study. Similarly, a shorter version of the cover letter was posted on social media sites.

Since nominal data was collected through the survey, the chi-square tests was used through the program NCSS. (Hintz, 2013).For this study, the chisquare statistical test was used to indicate if there was an association between two subgroups; demographics and food choice and food choice and reason for food choice.

\section{Results}

In total there were 118 participants who responded to the survey. Responses can be visualized in the graphs below. 


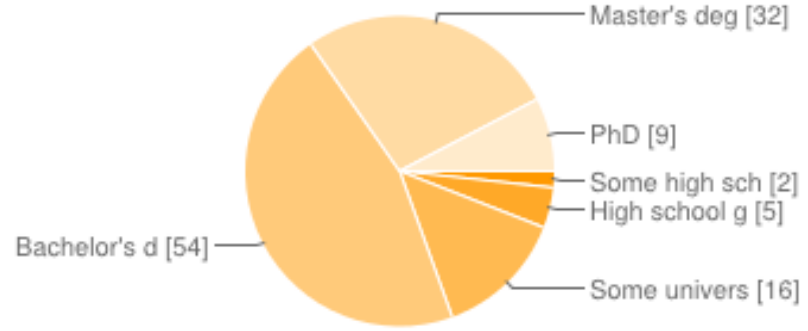

Figure 1 Education Responses

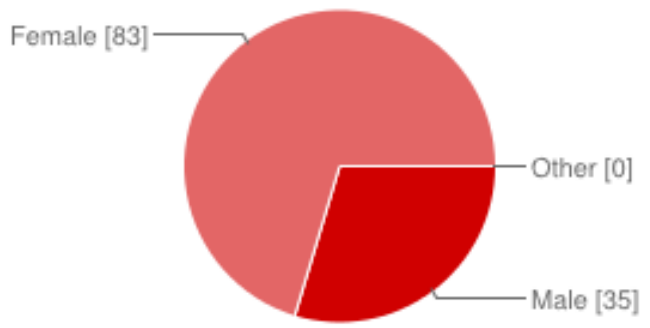

Figure 2 Gender Responses

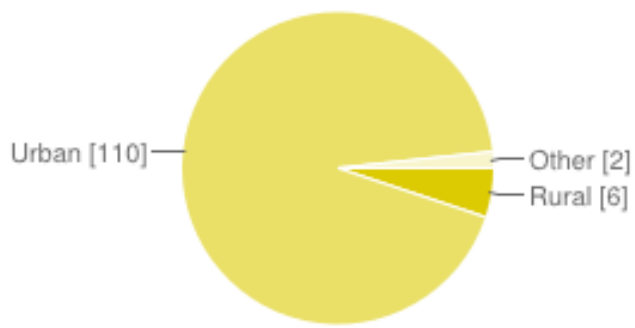

Figure 3 Settings Responses

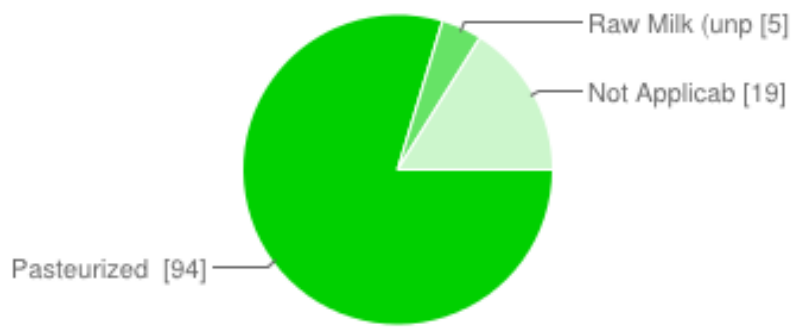

Figure 4 Milk Preference Responses

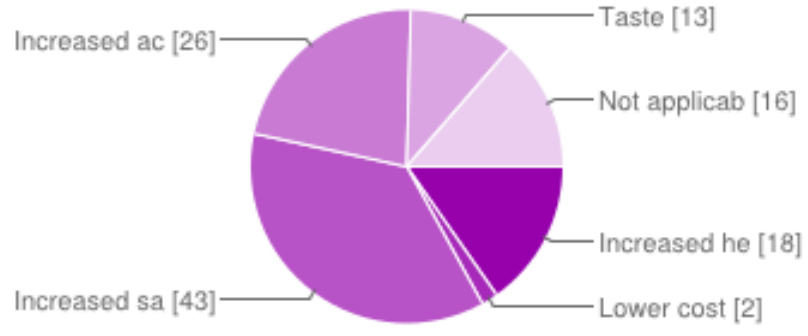

Figure 5 Milk Reasoning Responses

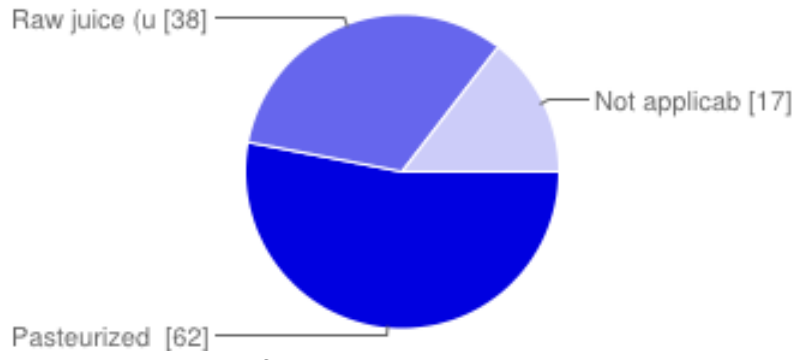

Figure 6 Juice Preference Responses

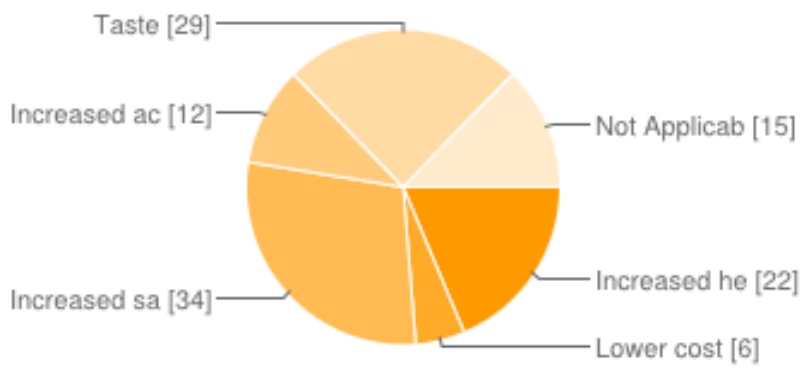

Figure 7 Juice Reasoning Responses

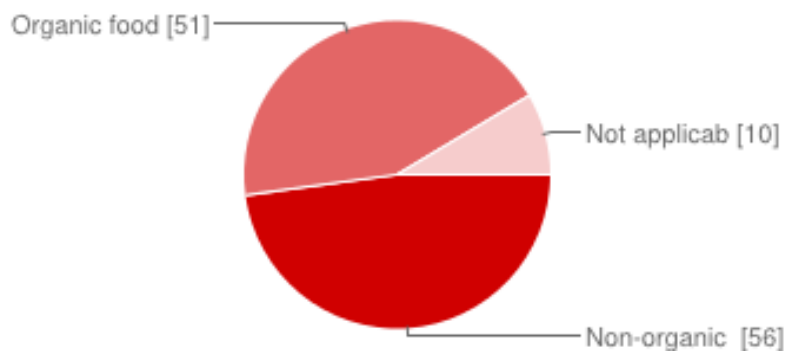

Figure 8 Organic Food Preference Responses

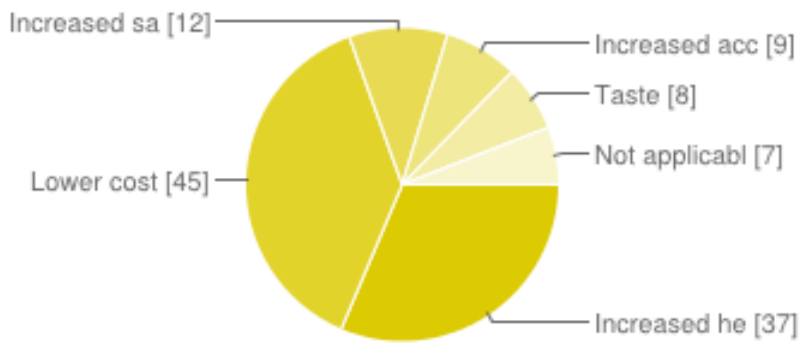

Figure 9 Organic Food Reasoning Responses

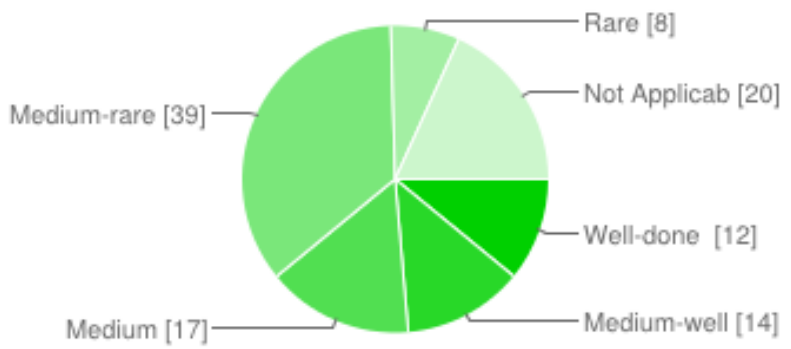

Figure 10 Steak Preference Responses 


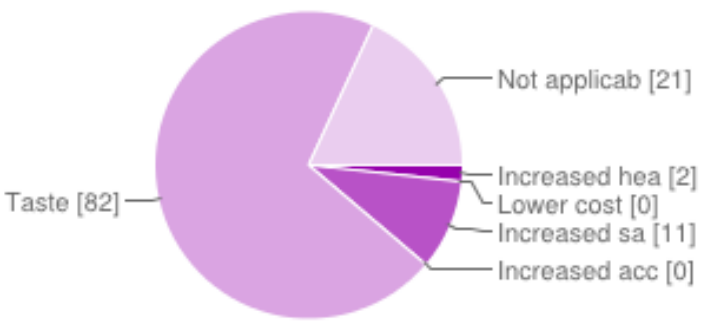

Figure 11 Steak Reasoning Responses

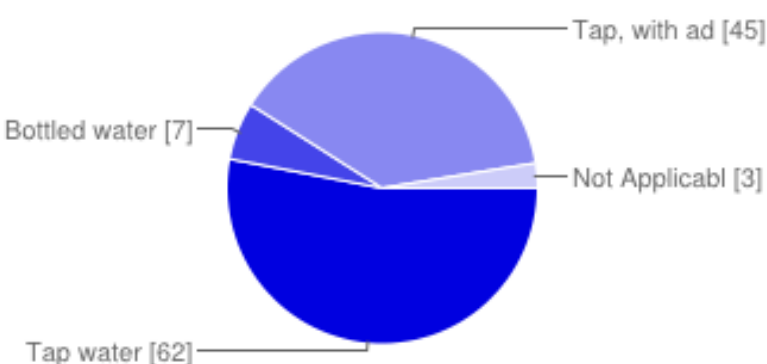

Figure 12 Water Preference Responses

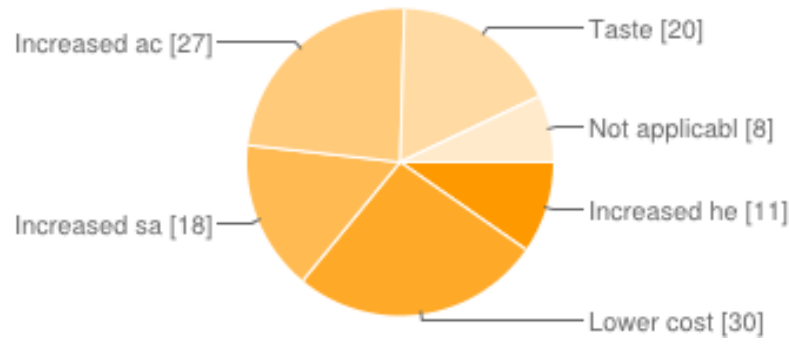

Figure 13 Water Reasoning Responses

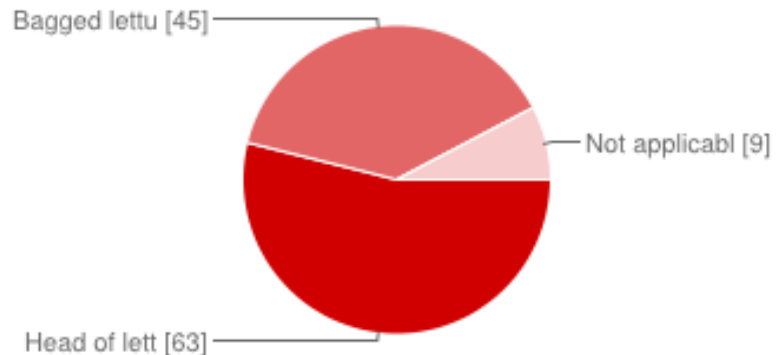

Figure 14 Lettuce Preference Responses

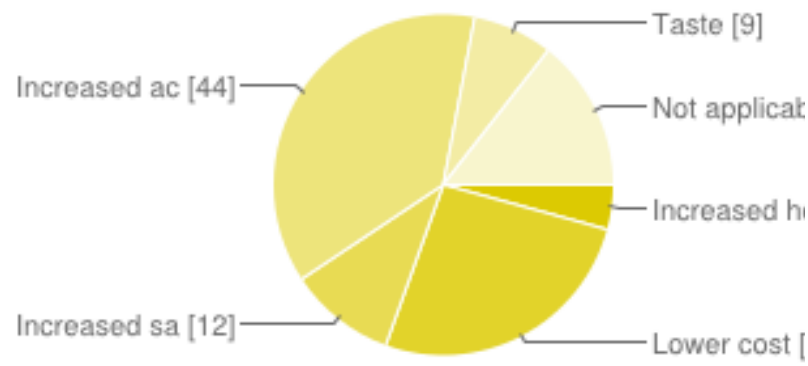

Figure 15 Lettuce Reasoning Responses

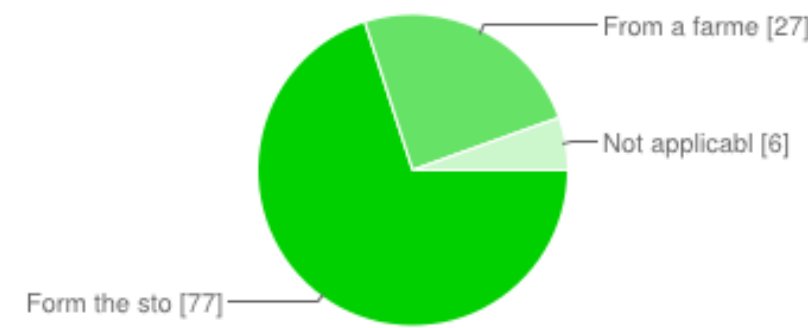

Figure 16 Egg Preference Responses

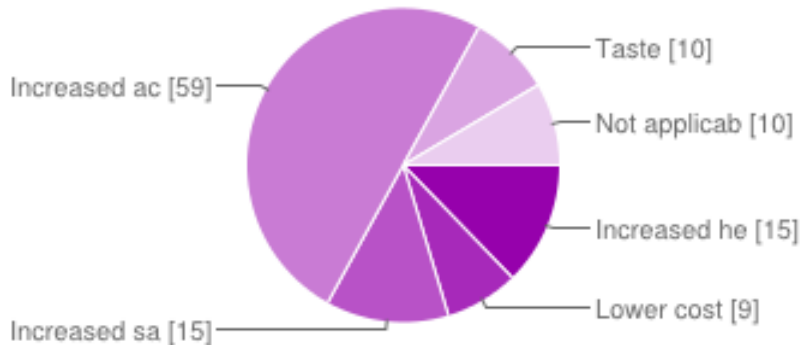

Figure 17 Egg Reasoning Responses

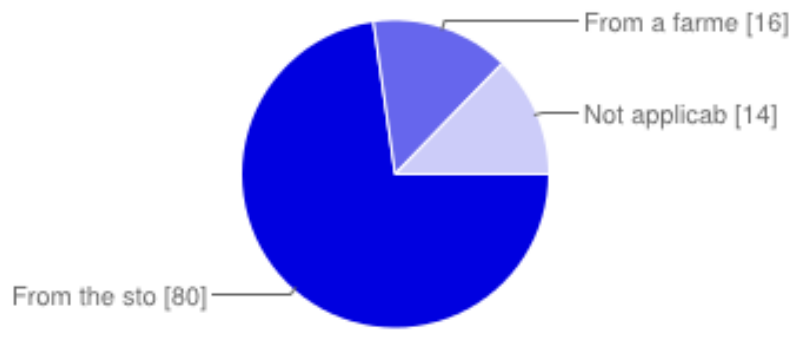

Figure 18 Meat Preference Responses

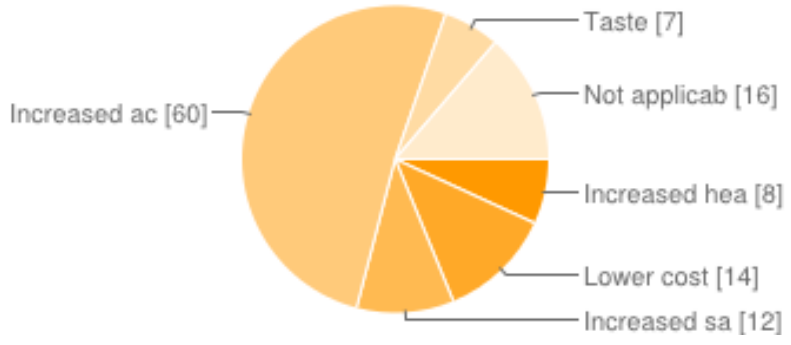

Figure 19 Meat Reasoning Responses

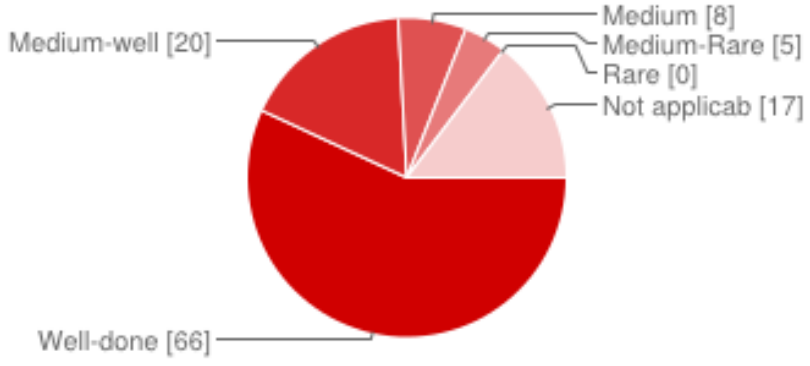

Figure 20 Hamburger Preference Responses 


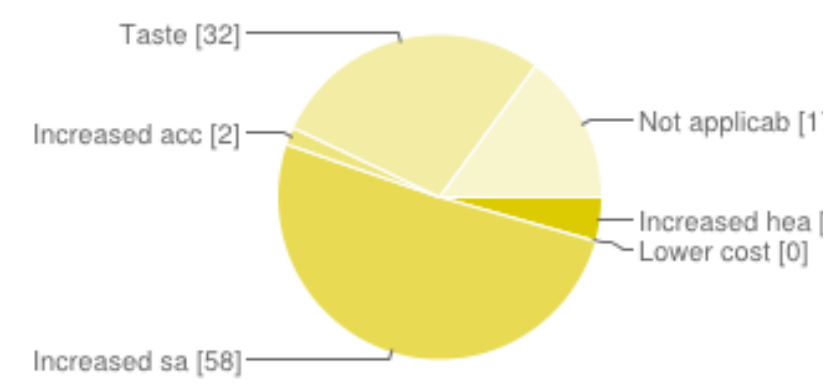

Figure 21 Hamburger Reasoning Responses

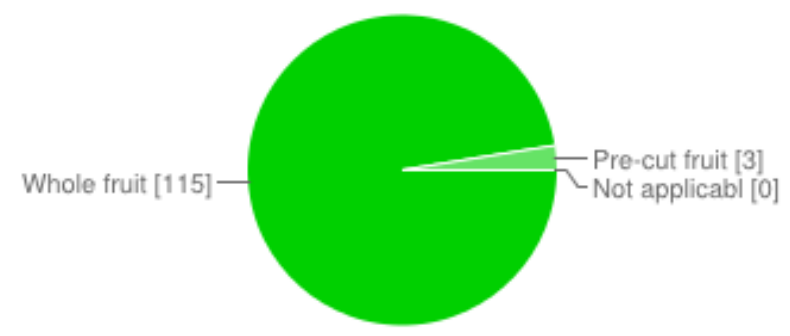

Figure 22 Fruit Preference Responses

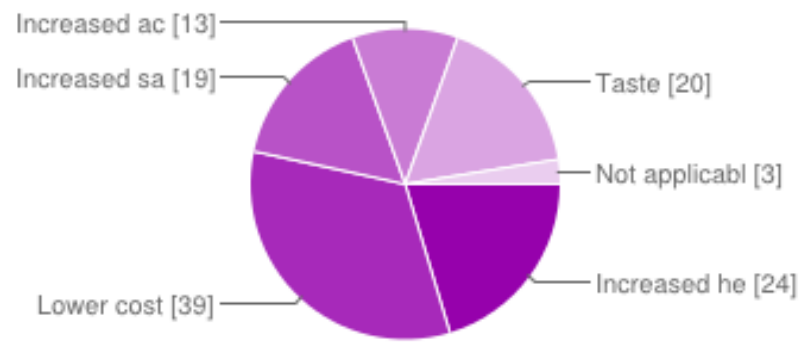

Figure 23 Fruit Reasoning Responses

\section{Demographics and food choice}

The only demographic that illustrated an association with a food choice was education. The association between education and both milk and organic/nonorganic food preferences was found to be statistically significant (p-value $<0.05$ ) with p-values of 0.01284 and 0.02217 respectively.

\section{Food choice and reasoning}

Thorough analysis indicated that all of the preferred food choices were associated with the reasoning behind that food choice, with the exception of whole vs. cut fruit $(\mathrm{p}$-value $=0.098)$. Those that were found to be associated were proven with p-values well below 0.01 (all p-values were less than 0.004).

\section{Alpha and beta errors}

In this study there was a potential for alpha errors to occur from all of the hypotheses tested. This occurs when the null hypothesis is incorrectly rejected, but rather the null hypothesis is in fact true (Heacock \&
Sidhu, 2013). Alpha errors could have likely occurred within the first sub-group of hypotheses, when testing associations between demographics and food choice. To minimize alpha errors the acceptable alpha must be lowered from 0.05 to 0.01 . In the case of associations between education and both milk and organic products the p-value is in-between 0.01 and 0.05 . If the acceptable p-value was lowered to 0.01 to reduce the chance for alpha errors then the associations between education and both milk and organic products would not be statistically significant, and therefore would be concluded that there was no association. This finding indicates that the association between education and both milk and organic products if exists is likely small.

In addition, there was also potential for beta errors. This occurs when there is failure to reject the null hypothesis, and an actual association likely exists (Heacock \& Sidhu, 2013). To minimize beta errors the sample size should be increased. In this study only 118 participants responded to the questionnaire, so beta errors were more likely than alpha errors.

\section{Discussion}

\section{Milk}

The statistically significant association between milk preference and its reasoning showed that even though very few participants preferred raw milk, those who did, did so due to raw milk's perceived health benefits and taste, whereas, those who preferred pasteurized milk did so due to safety and accessibility. This is in agreement with previous literature that stated that those who agree with the consumption of raw milk promote both its taste and health benefits over pasteurized milk (Jay-Russell, 2010).

Analysis indicated an association between education and milk choice and its reasoning. Percentages show that only $2.5 \%$ of those with at minimum a degree/diploma/certificate prefer raw milk, where as $17 \%$ of those without a post-secondary degree preferred raw milk. This study suggests that those with higher levels of education are more safety-sensitive than those with lower education, in regards to milk products (Rohr, Luddecke, Drusch, Muller, \& Alvensleben, 2005). This is potentially due to the fact that further education exposes consumers to more information regarding the true safety of food.

\section{Juice}

Similarly to milk, there was a statistically significant association between juice choice and the reason for it. Coinciding with milk, participants that prefer raw juice 
do so due to its health benefits and taste. Whereas those that prefer pasteurized juice do so due to safety and accessibility. As in the Odwalla case, raw juice is promoted for its natural element, indicating it may have more health benefits than pasteurized juice (Melvin, 2010). This may suggest that consumers are not well informed of the inherent risk that raw juice contains.

\section{Organic/non-organic food}

The majority of the participant with a higher level of education preferred non-organic food $(57 \%)$, whereas the majority with a lower level of education preferred organic $(72 \%)$. However those that prefer non-organic do so mainly because of its lower cost, and those that prefer organic do so mainly for the health benefits and safety of the food. Education may be needed to those who prefer organic food as its perceived health benefits and safety may not outweigh its potential risk, such as in the Odwalla case where the organic attribute of the juice led to the opportunity for contamination by pathogenic bacteria (Melvin, 2010). Consumers may view food products that lack of use of pesticides or addition processes contain more safety than those that undergo processes that eliminate pathogenic microorganisms.

\section{Cooking of steak and hamburgers}

Cooking of meat is a difficult topic, as it can be very subjective depending on the person. However due to the purposed of this study undercooked was considered medium-rare and rare for steak and medium, mediumrare and rare for hamburgers, as they are more at risk for potential contamination. For steak $100 \%$ of participants who preferred undercooked steak did so due to taste. Consumers should be informed on the potential risks associated with undercooked meat and so they can compare the benefits of taste to the consequences of foodborne illnesses.

With hamburgers, participants of this study seem to be well informed on the safety of undercooked hamburgers as all those who preferred cooked hamburgers did so due to safety. However, there were a few who prefer undercooked hamburgers, and similarly to steak, did so for taste. There was no association between steak and hamburger preferences and any demographic so it may be difficult to target specific groups regarding the risk associated with undercooked meat. However those who do prefer undercooked meat need to be informed that taste should not outweigh safety, especially in those who may be young, old, or immunocompromised.

\section{Water}

Approximately half of the participants preferred simple tap water over bottled and additional filtering. Those that prefer tap water do so mainly due to accessibility (48\%) and cost (43\%), and very rarely due to safety $(1.7 \%)$. Those who prefer tap water with additional filtering do so mainly due to taste $(37 \%)$ and safety (34\%), and the majority of those who prefer bottled do so due to safety (43\%). However previous literature state that tap water is likely safer than bottled water as it is regulated more strictly (Copes, Evans, \& Verhille, 2009). From these results it can be inferred that consumers may be misinformed regarding the safety of water sources. Consumers need more information on the safety of their water, what makes it safer, and what just makes it cosmetically more appealing.

\section{Source of egg and meat products}

The reason for preferring to purchase eggs or meat from either the grocery store or straight from the farmer was found to be associated with the reason for preferring either source. For eggs, participants that prefer a more direct sale (from the farmer) do so for health benefits $(52 \%)$ and taste $(37 \%)$, and those that prefer to purchase their eggs from the store do so mainly for the accessibility (74\%). Interestingly farmer's eggs are simply store eggs that have not been graded, meaning they could potentially be more at risk for contamination. When participants chose accessibility, it could mean that if farmer's eggs were more accessible they would probably purchase them or the graded eggs at the store. Consumers need to be more informed as to why graded eggs found at the store are at less risk for contamination, and so they will purchase them for their safety factor and not simply their accessibility.

\section{Vegetable and fruit}

Very few participants chose cut fruit over whole fruit, leaving the data difficult to analyze. On the other hand, half of participants prefer bagged (cut) lettuce over its whole counterpart. An association was found between lettuce preference and the reason for it. Those who prefer cut lettuce mainly do so for accessibility (ease of use) with $88 \%$, and those that prefer whole lettuce do so mainly for cost $(57 \%)$. A few participants $(17 \%)$ that prefer a head of lettuce do so for safety reasons, meaning they are well informed. Further processing of fruit or vegetables creates increased chance of contamination, and so whole is assumed safer than cut. Consumers that continuously purchase bagged lettuce should be informed of its risk, and should take precautionary measures (washing) to lower potential risk.

\section{Recommendations}

Based on this study less educated consumers need to be targeted for risk-messaging, specifically providing them with information on the potential risks associated with 
raw milk and organic food products. Moreover broad risk messaging needs to be performed to inform all consumers of the risks associated with potentially unsafe food items, specifically undercooked meats, ungraded eggs, raw milk and juice, organic/natural products and further processed vegetables/fruits.

This study opened the doors to figuring out what type of consumer prefers unsafe food products and so targeted risk-messaging can be created to education this specific consumer. As mentioned above those with lower education seems to prefer riskier foods than those with higher levels of education. Larger studies may be able to incorporate other demographics or facts to pinpoint consumers of unsafe food products.

\section{Limitations}

Due to the restricted funds, time, and human resources there were a few limitations of this study. The first limitation of this study was the method of data collection. Participants were only obtained through the internet, which mainly attracted participants living in urban settings. The lack of response from those living in rural settings led to a gap in the analysis. Therefore this study could not determine on how living setting reflect food preferences. The data collection method also affected the randomness of the study, and how well the sample participants accurately reflected the total population. The snow-ball effect lead to an increase in responses, however it decreased the variety of respondents. If more time was allotted a better method of data collection would be random dialling of telephone numbers, this would significantly increase randomness, as well as reach those living in all areas.

The second major limitation in this study was the subjectivity of some of the questions on the survey. It was difficult to truly analyze some responses as the interpretation of the participant was unknown. For example, cooking of meat is extremely subjective, as medium to one consumer may differ to another. Also the wording of a few questions may have led to misinterpretation by the participants. For example many participants stated that they preferred raw juice, which was surprising, however the question did not ask the freshness of the juice or timing of consumption. It is believed that many people prefer freshly squeezed juices which are considered raw, but low risk as they are likely consumed immediately. If the questionnaire was performed on the phone or in person it may have been easier to interpret responses, or answer any questions the participants may have had regarding the context of the questions.

\section{Future Research}

For further research on the topic of food preferences one could research in depth a specific food product of choice to look into obtain further detail on the consumer who prefers the unsafe option. For example comprehensive research could be performed on solely eggs bought straight from the farmer (ungraded) versus store bought eggs that are graded, and one could look into why a consumer believes farmer eggs have greater taste and health benefits over store-bought eggs.

Further research could also be performed on the safety of different products of the same type. More research needs to be performed to analyze if and how much safer tap water is from bottled water or processed fruits and vegetables than whole, or graded versus ungraded eggs. A thorough literature review of past outbreaks associated with these products could determine which type is more associated with contamination and is likely less safe. In addition to outbreak reports research should be performed on the nutritional value of different products of the same type, as many consumers believe potential health benefits outweigh potential risk.

In terms of risk messaging, further research should be performed to determine the best methods of informing the public regarding the safety of their food. With new technology and social media becoming popular there are likely new and ground breaking methods the public can be informed on their food choices.

\section{Conclusion}

The only demographic to have an association with food preferences is education, however not all food choices were found to be associated with education level. When association was found, it indicated that higher education was more associated with the safer food choices than lower education. The association between food preferences and its reasoning concludes that consumers who prefer opposing products do so for extremely different reasons. Consumers that prefer the more risky food products mainly do so for taste and potential health benefits. Public health officials need to ensure that consumers that prefer riskier products thoroughly understand the risks, so that they themselves can then truly compare the benefits of taste or perceived "healthiness" with the consequences of potential contamination and illness.

\section{Acknowledgements}

Production of this document was made possible through the Environmental Health Program, part of the School of Health Sciences at the British Columbia Institute of Technology. The researcher would also like to thank the faculty and 2014 Environmental Health class for all of their encouragement and support through the course of this research project. 


\section{Competing Interests}

The authors declare that they have no competing interests.

\section{References}

Agriculture and Agri-Food Canada. (2007). Consumer perceptions of food safety and quality: A closer look at the 2006 results. Agricultural Institute of Canada Conference. Retrieved from http://www.aic.ca/ conferences/http://www.aic.ca/conferences/pdf/2007/Pr esentations/Diane_Jebson.pdf

Colonna, A., Durham, C., \& Meunier-Goddick, L. (October 2011). Factors affecting consumers' preference for and purchasing decisions regarding pasteurized and raw milk specialty cheeses. Journal of Dairy Science, 94(10), 5217-5226.

Copes, R., Evans, G. M., \& Verhille, S. (2009). Bottled vs tap water. BC Medical Journal, 51(3), 112-113. Retrieved from http://www.bcmj.org/council-healthpromotion/bottled-vs-tap-water

De Jonge, J., van Trijp, H., Renes, R. J., \& Frewer, L. (2007). Understanding consumer confidence in the safety of food: Its two-dimensional structure and determinants. Risk Analysis, 27(3), 729-740.

De Jonge, J., van Trijp, J. C. M., van der Lans, I.A., Renes, R.J., \& Frewer, L.J. (2008). How trust in institutions and organizations builds general consumer confidence in the safety of food. A decomposition of effects. Appetite, 51, 311-317

Dillaway, R., Messer, K. D., Bernard, J. C., \& Kaiser, H. M. (2011). Do consumer responses to media food safety information last? Applied Economic Perspectives and Policy, 33(3), 363-383.

Fowler, Jr. F, J. (2002). Survey Research Methods ( $3^{\text {rd }}$ ed.) Applied social research methods series (Volume 1). Thousand Oaks, CA: SAGE Publications Inc. Franchi, M. (March 2012). Food choice: beyond the chemical content. International Journal of Food Science and Nutrition, 63, 17-34.

Greenberg, J., \& Elliot, C. (2009) A cold cut crisis: Listeriosis, Maple Leaf Foods, and the politics of apology. Canadian Journal of Communication, 34(2), 189-204.

Heacock, H. \& Sidhu, B. (2013) ENVH 8400: Research methods, module 4-5: [PowerPoint slides]. D2L Website. Retrieved from https://learn.bcit.ca/d21/ le/content/143039/viewContent/855510/View
Hintz, J. (2013). NCSS 9. NCSS, LLC. Kaysville, Utah, USA. www.ncss.com

Hu, Z., Morton, L. W., \& Mahler, R. L. (2011). Bottled water: United States consumers and their perceptions of water quality. International Journal of Environmental Research and Public Health, 8, 565-578.

International Association for Food Protection. (2011). Procedures to Investigate Foodborne Illness ( $6^{\text {th }}$ ed.) New York: Springer.

Jay-Russell, M. T. (2010). Raw (unpasteurized) milk: Are health-conscious consumers making an unhealthy choice? Clinical Infectious Diseases, 51(12) 1418-1419.

McFadden, D. T., Blandon, S., Bunning, M., Kendall, P., Troxell-Alrich, H., Bruning, J., \& Yeh, S. (March 2010). Consumer awareness and response to produce food safety issues. Journal of Food Distribution Research, 41(1), 108-114.

Melvin, S. P. (2010) Capstone case study: The Odwalla Juice Company crisis. The legal environment of business: A managerial approach: Theory to practice. Mcgraw-Hill Education.

Rohr, A., Luddecke, K., Drusch, S., Muller, M.J., \& Alvensleben, R. v. (2005). Food quality and safetyconsumer perception and public health concern. Food Contro,l 16(8), 649-655.

Rosati, S., \& Saba, A. (2004). The perception of risks associated with food-related hazards and the perceived reliability of sources of information. International Journal of Food Science and Technology, 39, 491-500.

The Weston A. Price Foundation. (2013). Fresh, unprocessed (raw) whole milk: Safety, health and economic issues. Retrieved from http://www.realmilk.co $\mathrm{m} /$ safety/fresh-unprocessed-raw-whole-milk/

TSN Opinion and Social. (2010). Special Eurobarometer 354: Food-related risks. Survey requested by the European Food Safety Authority. Retrieved from http://www.efsa.europa.eu/en/factsheet/ docs/sreporten.pdf

Ward, L. A., Cain, O. L., Mullally, R. A., Holliday, K. S., Wernham, A. G., Baillie, P. D., \& Greenfield, S. M. (2009). Health beliefs about bottled water: A qualitative study. BioMed Central Public Health 9:196. Retrieved from http://www.biomedcentral.com/content/pdf/14712458-9-196.pdf 
